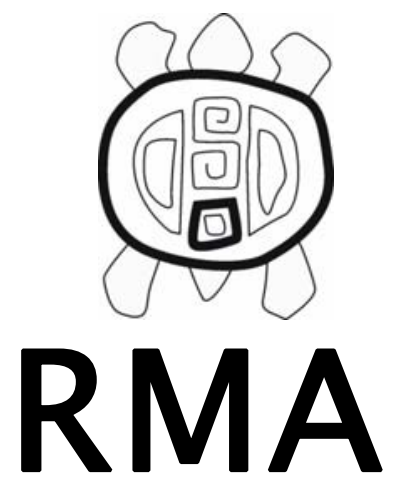

Antropología Social

\title{
Cartografía de las publicaciones periódicas judías de izquierda en Argentina, 1900-1953
}

\author{
Alejandro Dujovne \\ Becario doctoral CONICET/ Museo de Antropología \\ Facultad de Filosofía y Humanidades, \\ Universidad Nacional de Córdoba \\ e Instituto de Desarrollo Económico y Social (IDES) \\ aledujovne@gmail.com
}

\begin{abstract}
Resumen
La fuerte inversión política y cultural en la palabra impresa que tuvo lugar dentro del mundo cultural judío argentino a lo largo del siglo XX se mostró especialmente intensa y rica en el arco ideológico de la izquierda. Así, sobre la base de un prolongado trabajo de registro y sistematización de las publicaciones periódicas judías impresas en Buenos Aires a lo largo del siglo XX, el artículo se concentra en el análisis del conjunto de publicaciones de izquierda editadas entre 1900 y 1953. En este sentido, se propone un mapeo de la diversidad de emprendimientos y a partir de él un primer esbozo de periodización a partir del cual resulte posible aproximarnos a los rasgos generales de la emergencia y las transformaciones socio-históricas de un espacio específico de publicaciones judías de izquierda. De este modo, el texto expone los contornos de un universo denso de producción, circulación y consumo de bienes simbólicos estructurado sobre dos lenguas y conformado por un diverso conjunto de agentes culturales y políticos situados en el país y en el exterior. La objetivación de este espacio mediante una aproximación cartográfica como la que aquí se propone abre un terreno de problemas e hipótesis de investigación aún no explorado.
\end{abstract}

Palabras clave: judaísmo - judíos - periódicos de izquierda - cartografía - Argentina

Cartography of Jewish left-wing periodicals in Argentina, 1900-1953

\begin{abstract}
The strong political and cultural investment in the printed word that took place within the Argentine Jewish cultural world throughout the twentieth century was particularly intense and rich in the arc of the ideological left. Thus, based on a lengthy work of record and systematization of Jewish periodicals printed in Buenos Aires along the twentieth century, the article focuses on the analysis of the left-wing periodicals published between 1900 and 1953. In this regard, it proposes a mapping of the diversity of enterprises, and from it a first outline of periodization from which it is possible to reach the general features of the emergency and the socio-historical transformations of a specific area of Jewish left-wing publications. In this sense, the text describes the contours of a dense universe of production, circulation and consumption of symbolic goods structured on two languages and consisting of a diverse set of cultural and political actors located in the country and abroad. The objectification of this space through a cartographic approximation like the one propposed here opens an area of research problems and hypothesis not yet explored.
\end{abstract}

Keywords: Judaism - Jews - left-wing periodicals - cartography - Argentina

El volumen, diversidad, y carácter transnacional de la producción, circulación y consumo de publicaciones periódicas judías en Argentina a lo largo del siglo XX recortan un espacio diferenciado respecto del más amplio universo de la palabra impresa en el país. Dentro de este espacio los boletines, periódicos y revistas de izquierda ocupan un lugar de relevancia. En este sentido, el presente estudio propone una primera aproximación al espacio de la palabra impresa judía de izquierda en Argentina entre 1900 y 1953 que pueda dar cuenta de los rasgos generales de su emergencia así como de sus transformaciones a lo largo del período considerado.' Para tornar visible el espacio de publicaciones judías de izquierda y contribuir a su inteligibilidad realizaremos aquí un mapeo de la diversidad de emprendimientos y a partir de él

Recibido 08-09-2008. Recibido con correcciones 15-09-2008. Aceptado 30-09-2008 
un primer y muy provisorio esbozo de periodización.

El presente estudio es el primer análisis derivado del registro de publicaciones periódicas judías editadas en Buenos Aires que hemos elaborado como parte de una investigación más amplia que procura comprender el lugar de la palabra impresa en la modelación de la vida judía en Argentina. A diferencia de los abordajes parciales existentes, este registro es el resultado de un trabajo sistemático que busca dar cuenta de manera exhaustiva del arco de publicaciones judías editadas en la Ciudad de Buenos Aires a lo largo de un siglo. La construcción de bases de información seriada resulta un paso necesario para objetivar un espacio de publicaciones periódicas y agentes que de otro modo pasaría inadvertido. De la misma manera, es a partir del análisis de estas series que resulta posible acercarnos a un conjunto de fenómenos y procesos sociológicos generales de relevancia. Cabe aclarar, sin embargo, que somos concientes de que esta tarea no es sino un primer paso en la investigación, pues, tal como señala con claridad Roger Chartier, la aproximación cuantitativa por sí misma no resulta suficiente para comprender la singularidad de cada objeto ni las especificidades sociales y culturales que éste nos puede revelar. ${ }^{2}$

Entre 1898, año de aparición del primer periódico judío en el país, y 1989, hemos identificado 337 publicaciones periódicas judías. ${ }^{3}$ Este registro comprende una amplia gama de formatos (revistas, periódicos, boletines), frecuencias (diarios, semanales, quincenales, etc.) duraciones (desde algunos días de existencia hasta más de 70 años de vida), y tipos y grados de vinculación institucional (que van desde el polo de independencia al polo de la subordinación); así como también una singular diversidad lingüística (idish, castellano, hebreo, alemán, húngaro, árabe, etc.), ideológica (integracionismo liberal, sionismo, sionismo socialista, bundismo, anarquismo, comunismo), y temática (información general, políticas, culturales, infantiles, cooperativistas, etc.).

Entre las 337 publicaciones registradas, encontramos 97 boletines, revistas y periódicos que, en sus distintas variantes, dan forma al abanico de publicaciones de izquierda. ${ }^{4}$ Este conjunto se compone de las siguientes publicaciones: 3 anarco-comunistas, 7 anarquistas, 7 bundistas, 37 comunistas (incluyendo a periódicos filocomunistas), 1 comunista penelonista, 2 comunistas producto de escisiones intrajudías, 23 sionistas socialistas, 13 obreras, 1 socialista, 2 progresistas de carácter general, y 1 definida como marxista.

La elaboración de un mapa de las publicaciones periódicas judías de Buenos Aires que dé cuenta tanto de su diversidad como de sus niveles diacrónico y sincrónico entraña dos tipos de aportes historiográficos distintos. En primer lugar, esta aproximación que por analogía denominamos cartográfica resulta un instrumento heurístico fundamental para tornar visible de manera simple la heterogeneidad de visiones y multiplicidad de actores que convergieron a lo largo de un período prolongado en la formación de un espacio local de confrontación políticocultural específicamente judío. De este modo, por contraste con la mayoría de los estudios de historia judía argentina en los que se privilegia la observación de una corriente ideológica y cultural particular y, en el mejor de los casos, su enfrentamiento con otra expresión política, la aproximación que aquí sostenemos pretende contribuir al trazado de un escenario amplificado en el cual situar y restituir el peso específico de las manifestaciones y disputas singulares que allí tuvieron lugar. Por otra parte, es necesario señalar que este instrumento tiene un valor analítico particular para el caso judío en el que la palabra impresa aparece como un medio de intervención político y cultural altamente valorado. En segundo término, la confección de este mapa resulta una contribución sustantiva en los estudios de la prensa y de la historia intelectual en el país en la medida en que ilumina un mundo social hasta el momento soslayado de las investigaciones, que participa de manera diferenciada del espacio político y cultural argentino. En efecto, al observar los problemas puestos en juego, las referencias ideológicas, las tensiones lingüísticas, los múltiples lazos que anudan a este espacio con el exterior y los actores involucrados emerge un espacio dinámico que refracta de acuerdo a su propia lógica los acontecimientos y procesos del contexto local.

\section{Un primer ensayo de periodización}

Con cifras de publicaciones algo distintas a las aquí identificadas, Bilsky (1987) propone como modo posible para la observación de las transformaciones del campo político judío progresista el análisis de la prensa de izquierda a partir del momento de aparición de cada publicación en términos de décadas (1901-1940) y de su adhesión ideológica o institucional. La distribución por décadas de las 54 publicaciones registradas por su equipo de investigación permitiría observar, según su punto de vista, las tendencias al crecimiento o decrecimiento de cada corriente. A partir del examen de estas tendencias, Bilsky demuestra la progresiva polarización del campo de publicaciones periódicas de izquierda entre el sionismo socialista y el comunismo. Entre 1901 y 1940 los periódicos anarquistas, bundistas, y en menor medida los específicamente obreros, pierden terreno de manera progresiva frente al crecimiento del comunismo a partir de la década de 1920 y a la sostenida consolidación del sionismo socialista en la década de 1930. 
Expandiendo tres nuevas décadas (1941-1980) el esquema propuesto por Bilsky y modificando los datos a partir de la información recabada (que aun presenta algunas lagunas para la segunda mitad del siglo), es posible obtener una imagen algo distinta de la presentada por el autor. En particular respecto a la polarización entre el sionismo socialista y el comunismo en las décadas de 1920 y 1930. A diferencia de dicha polarización, observamos que durante esas décadas se produce el claro dominio del comunismo por sobre el resto de las nuevas publicaciones de izquierda. Es recién en la década de 1950 , y a partir de la combinación entre la tendencia decreciente de las publicaciones comunistas y la desaparición de nuevas publicaciones periódicas de otras corrientes (la publicación anarquista consignada en la Tabla 1 en la década de 1950 corresponde a un boletín), que se genera una sostenida polarización entre comunismo y sionismo socialista.

A pesar de su importancia como indicador de ciertas tendencias políticas de la vida judía, el número de nuevos emprendimientos periódicos ordenados por años no puede considerarse un reflejo directo de los procesos políticos. Valen para ello al menos dos razones. En primer lugar, la disposición para la edición de nuevas hojas impresas puede variar notablemente de una organización y de un tiempo a otro sin que ello responda de manera necesaria a cambios en el espacio político judío. En segundo término, para un análisis más completo de esta relación deben tenerse en cuenta tanto la vida de cada publicación, cifrada en números editados y duración de cada emprendimiento, como del tipo de publicación de la que se trate: boletín, revista, periódico tabloide, diario, etc. Cabe señalar sin embargo, que, a diferencia de la aproximación ensayada por Bilsky, el presente trabajo pone su foco de atención sobre las publicaciones periódicas de izquierda y sobre su relación con las transformaciones del espacio político judío, y no sobre las organizaciones políticas en sí.

Ahora bien, más allá de la validez general de estas consideraciones, la diferencia entre los propósitos de ambos estudios exige tomar distancia de otro aspecto del análisis de Bilsky. Si bien la Tabla expone con claridad algunas tendencias generales a lo largo del siglo, la opción por una rígida periodización basada en décadas impide avanzar en una comprensión que dé cuenta de la complejidad y dinámica de la producción de las publicaciones periódicas judías de izquierda. En este sentido, resulta necesario contemplar una serie de procesos y acontecimientos sociales, políticos, económicos y culturales que son tanto la condición de posibilidad de la prensa judía de izquierda como su ámbito de intervención. Considerando la amplitud del período comprendido, así como el número y diversidad de las publicaciones abarcadas, nos hemos concentrado sobre una serie limitada de procesos y acontecimientos que entendemos son fundamentales para comprender las transformaciones del espacio de la palabra impresa judía de izquierda. De este modo, a partir del análisis de las relaciones entre las transformaciones de este espacio y un conjunto significativo de cambios políticos, sociales, económicos y culturales del colectivo judío argentino, podemos esbozar la siguiente

\begin{tabular}{|c|c|c|c|c|c|c|c|c|c|c|c|c|c|c|c|c|c|c|}
\hline \multirow{2}{*}{$\begin{array}{c}\text { Décadas } \\
\text { Tendencia Ideol. } \\
\end{array}$} & \multicolumn{2}{|c|}{$\begin{array}{c}1901- \\
1910\end{array}$} & \multicolumn{2}{|c|}{$1911-1920$} & \multicolumn{2}{|c|}{$\begin{array}{c}1921- \\
1930\end{array}$} & \multicolumn{2}{|c|}{$\begin{array}{c}1931- \\
1940\end{array}$} & \multicolumn{2}{|c|}{$\begin{array}{c}1941- \\
1950\end{array}$} & \multicolumn{2}{|c|}{$\begin{array}{c}1951- \\
1960\end{array}$} & \multicolumn{2}{|c|}{$\begin{array}{c}1961- \\
1970\end{array}$} & \multicolumn{2}{|c|}{$\begin{array}{c}1971- \\
1980\end{array}$} & \multicolumn{2}{|c|}{ Totales } \\
\hline & No & $\%$ & $\mathrm{~N}^{\circ}$ & $\%$ & No & $\%$ & $\mathrm{~N}^{\circ}$ & $\%$ & No & $\%$ & No & $\%$ & No & $\%$ & No & $\%$ & No & $\%$ \\
\hline Comunistas & - & - & - & - & 10 & $45 \%$ & 15 & $49,5 \%$ & 8 & $57,1 \%$ & 1 & $25 \%$ & 3 & $42,9 \%$ & - & - & 37 & $\begin{array}{c}38,1 \\
\%\end{array}$ \\
\hline $\begin{array}{l}\text { Escisiones } \\
\text { Comunistas }\end{array}$ & - & - & - & - & 1 & $4,5 \%$ & - & - & - & - & 1 & $25 \%$ & 1 & $14,2 \%$ & - & - & 3 & $3,1 \%$ \\
\hline Sionistas Socialistas & 4 & $44,4 \%$ & 1 & $10 \%$ & 2 & $9 \%$ & 8 & $26,4 \%$ & 4 & $28,6 \%$ & 1 & $25 \%$ & 3 & $42,9 \%$ & - & - & 23 & $\begin{array}{c}23,8 \\
\% \\
\end{array}$ \\
\hline Obreras & - & - & 5 & $50 \%$ & 4 & $18 \%$ & 4 & $13,2 \%$ & - & - & - & - & - & - & - & - & 13 & $\begin{array}{c}13,4 \\
\% \\
\end{array}$ \\
\hline Bundistas & 1 & $11,1 \%$ & 1 & $10 \%$ & 3 & $13,5 \%$ & 1 & $3,3 \%$ & 1 & $7,1 \%$ & - & - & - & - & - & - & 7 & $7,2 \%$ \\
\hline Anarquistas & 3 & $33,3 \%$ & 1 & $10 \%$ & - & - & 1 & $3,3 \%$ & 1 & $7,1 \%$ & 1 & $25 \%$ & - & - & - & - & 7 & $7,2 \%$ \\
\hline Anarco-Comunistas & - & - & 1 & $10 \%$ & 2 & $9 \%$ & - & - & - & - & - & - & - & - & - & - & 3 & $3,1 \%$ \\
\hline Otras & 1 & $11,1 \%$ & 1 & $10 \%$ & - & - & 1 & $3,3 \%$ & - & - & - & - & - & - & 1 & 100 & 4 & $4,1 \%$ \\
\hline Total & 9 & $100 \%$ & 10 & $100 \%$ & 22 & $100 \%$ & 30 & $100 \%$ & 14 & $100 \%$ & 4 & $100 \%$ & 7 & $100 \%$ & 1 & $100 \%$ & 97 & $100 \%$ \\
\hline
\end{tabular}

Tabla 1. Número y porcentaje de nuevas publicaciones políticas ordenadas según corriente ideológica en base a décadas entre 1901 y 1980 
periodización: 1- prehistoria de las publicaciones periódicas judías argentinas (etapa previa a 1906, año de la publicación del primer periódico judío de izquierda), 2- primera prensa judía de izquierda (1906-1917), 3- emergencia y consolidación del comunismo (1918-1940), ${ }^{5}$ y 4 - ascenso social, apuesta cultural y cambio lingüístico (1941-1953). ${ }^{6}$

\section{Prehistoria de las publicaciones periódicas judías de izquierda en el país}

Si 1898 marca el inicio de la prensa judía en Argentina con la aparición del periódico en idish Viderkol (El ECo), 1906 señala el comienzo de la prensa política judía de izquierda. En efecto, en dicho año el recién creado Centro Sionista Socialista, precursor de la rama local del partido sionista socialista Poalei Tzión, edita el diario en idish Najriten (Noticias). ${ }^{7}$ A partir de él, y con la multiplicación de publicaciones de izquierda que le suceden, comienza a tomar forma un espacio singular de intervención y confrontación ideológica y política. No obstante, sería un error creer que las ideas y el activismo político que impulsan este tipo de intervención escrita, nacen con la aparición de la prensa local de izquierda o con la organización de las distintas corrientes políticas judías en el país. Por el contrario, tanto las ideas como la experiencia política de estos militantes provienen de las batallas ideológicas y políticas libradas en el centro y este de Europa hacia fines del siglo XIX y principios del XX.

La marginación y violencia operada contra las masas judías en el imperio zarista sienta las condiciones para la evolución de organizaciones e ideologías políticas que procuran revertir esta situación. Así, en el espectro ideológico de la idishland (zona de habla idish de Europa Central y Oriental), son las ideas de izquierda las que adquieren preponderancia. Dentro de la diversidad de opciones que este campo ideológico ofrece, los judíos se ubican y organizan políticamente en algún lugar situado entre un polo nacional y otro de clase. Las disputas dentro de esta línea de tensión convierten a ciertos tópicos como la lengua, el territorio, el Estado, la cultura, la nación o la idea de diáspora, en problemas ideológicos cruciales.

Este marco nos permite situar y diferenciar las dos organizaciones políticas que sientan las bases de la izquierda judía en el país: el sionismo socialista y el Bund. ${ }^{8}$ El Poalei Tzión, cuyo nacimiento se produce a fines del siglo XIX en Ucrania, plantea la necesidad de que los judíos, en cuanto nación privada de territorio y por ello destinada a ocupar una posición anómala dentro del sistema productivo capitalista, funde su autonomía en un territorio propio. Este partido representa uno de los intentos por hacer converger el pensamiento marxista con la reivindicación nacional. A pesar que Palestina aparece como la región económica y culturalmente óptima para este destino, la valoración de la vida judía en la diáspora y del idish oscilará entre un polo positivo y otro negativo de acuerdo al momento histórico. ${ }^{9}$ A diferencia del Poalei Tzión, el Bund, la Liga de trabajadores de Lituana, Polonia y Rusia, propone la combinación del socialismo con un tipo de autonomismo nacional, no territorial, basado en la cultura idish. Esta organización nace en 1897 en Lituania, el corazón del mundo cultural judío laico. La resignificación que sus dirigentes hacen del idish, de instrumento de agitación del proletariado judío a fundamento de un mundo cultural singular, implicará, al mismo tiempo, su transformación ideológica: de partido clasista antes que judío pasará a postular la existencia e importancia política de la nación judía.

De esta manera, cuando los activistas políticos arriban al país huyendo de la represión tras la frustrada revolución de 1905 y deciden recrear en Argentina sus organizaciones políticas, las grandes líneas y problemas ideológicos ya han sido planteados. Sin embargo, a medida que estas organizaciones políticas se desarrollan en el país, las condiciones sociales y políticas argentinas y judías las conducen a una progresiva redefinición de sus prácticas y posiciones. En otras palabras, así como Argentina no es Polonia, ni la colectivdad judía local es igual a la de los países del centro y este europeo, tampoco lo pueden ser los desarrollos ideológicos ni las prácticas políticas.

Por otra parte, al igual que con el nacimiento de las fuerzas políticas, en materia de prensa judía en Argentina la etapa previa a la aparición de Najriten debe ser contemplada como pieza necesaria de la constitución del espacio de publicaciones del cual participará la prensa de izquierda. Esta etapa se caracteriza por englobar a los primeros ensayos periodísticos. Lázaro Schallman indica que el punto de partida del periodismo judío argentino debe situarse en 1892 , seis años antes de la publicación de Viderkol, pues ya desde ese momento Buenos Aires cuenta con inmigrantes que actúan como corresponsales de diarios judíos europeos. Luego, a partir de 1898 y hasta la publicación de Najriten en 1906, se editan en el país 8 publicaciones de distinta calidad y duración, de las que dos, Der Zionist (EI Sionista, 1899-1904) en idish y El Sionista (19041906) en castellano, en calidad de voceros de dos organizaciones sionistas, cumplen un rol fundacional al introducir de manera sostenida una corriente ideológica dentro del campo de la palabra impresa judía en argentina. A esto hay que añadir la circulación y consumo local de publicaciones periódicas de izquierda editadas en otros países. ${ }^{10}$ Así, cuando los dirigentes del Poalei Tzión deciden editar un periódico propio para difundir sus ideas, comienzan a participar de un espacio de publicaciones periódicas que ya ha comenzado a tomar forma. 


\section{Primera prensa periódica judía de izquierda}

El período comprendido entre la aparición del primer periódico judío de izquierda en el país (1906), y la confluencia de un conjunto de acontecimientos ocurridos entre 1917 y 1918 que reordenan la vida política judía en Argentina (la Declaración Balfour de 1917, la Revolución Rusa del mismo año, y la fundación del diario Di Presse en 1918), se caracteriza por una notable diversificación interna y por la consolidación de un espacio de producción, circulación y consumo de publicaciones periódicas diferenciado del medio argentino. Entre 1906 y 1917 hemos identificado 38 publicaciones periódicas nuevas de muy diversa índole. ${ }^{11}$ Del conjunto de publicaciones que dan forma y singularidad a este período, se destaca por su relevancia en la historia de la colectividad judía argentina, el diario en idish Di Idishe Tzaitung (El Diario Israelita) que comienza a editarse en 1914 y culmina en 1974, y cuyo público está compuesto, a grandes rasgos, por los sectores más tradicionalistas y establecidos de la colectividad judía.

Entre las 38 publicaciones identificadas se distinguen 16 de explícito carácter ideológicopolítico, de las que 13 se ubican dentro del espectro de la izquierda. Las tres restantes representan dos variantes del sionismo no socialista. Las publicaciones de izquierda se distribuyen de la siguiente manera: 4 sionistas socialistas, 4 anarquistas, 2 bundistas, 2 obreras, y 1 socialista de orientación "asimilacionista». Resulta significativo el hecho de que 9 de estas 13 publicaciones se editen por primera vez entre 1906 y 1909, y que ninguna de ellas sobreviva al parteaguas de 1910.

Esta concentración de publicaciones de izquierda en el lapso de los casi cinco años comprendidos entre 1906 y 1910 no es, sin embargo, casual. Tal como antes señalé, la represión ejercida por el zar tras la frustrada revolución de 1905, que tiene como objeto predilecto de su violencia a los judíos tras la acusación de ser los instigadores de la revuelta, trae al país una corriente de obreros ligados a distintas tradiciones de izquierda. De esta suerte, en 1906 se funda el primer centro sionista socialista en Buenos Aires, así como la primera organización anarquista judía en el país, Arbeter Fraind (El Amigo del Trabajador). Al año siguiente se crea la rama local del partido Poalei Tzión, hacia el que confluye el centro sionista socialista, y se funda la organización socialdemócrata bundista Avangard (La Vanguardia). ${ }^{12}$ De este espacio se desprende de forma temprana un pequeño grupo de judíos de habla rusa que, bajo el modelo iskrista de asimilación al medio cultural dominante, da origen al Centro Avangard. Parte importante de la actividad de estas corrientes se centró en la organización de bibliotecas y en la publicación de periódicos. De hecho, estas organizaciones políticas funcionan desde su nacimiento y hasta 1910 dentro de, o en torno a, la Biblioteca Rusa, la cual, aun cuando sostiene un carácter panruso, se halla mayoritariamente compuesta por trabajadores e intelectuales judíos.

La represión desplegada por policías y bandas «patrióticas» contra el movimiento obrero y los partidos de izquierda tras las huelgas y atentados anarquistas de 1909 y 1910 , interrumpen bruscamente la actividad política de izquierda que hasta ese momento se desarrolla en la «calle judía». El local de la Biblioteca Rusa es destruido, la mayoría de sus libros quemados en Plaza Congreso, y los dirigentes poaleisionistas León Jazanovich y Zalman Sorkin expulsados bajo el amparo de la Ley de Residencia. ${ }^{13}$ Como consecuencia de estos acontecimientos, el Poalei Tzión se reduce hasta casi desaparecer. Retorna a la actividad primero con timidez en 1916 y luego con fuerza hacia 1918. El núcleo bundista se concentra en la creación de una nueva biblioteca, en la reorganización de las fracciones sindicales surgidas antes de 1910 y en la edición del periódico semanal Unzer Wort (Nuestra Palabra) en 1913. Asimismo, modifica su anterior posición y opta por un mayor acercamiento al Partido Socialista. Los anarquistas judíos, por su parte, orientan su militancia de manera decidida hacia la actividad cultural y educativa y en 1916 conforman la Idishe Ratsionalistishe Ligue (la Liga Racionalista Judía).

Según Bilsky (1987), la actividad gremial judía durante esta etapa es débil. Si bien se crean algunos sindicatos judíos autónomos (gorreros, actores y panaderos) y se organiza una sección judía dentro un sindicato general (sastres), la actividad gremial específicamente judía a lo largo de este período es relativamente breve. Razón por la cual solo hallamos dos periódicos que pueden ser definidos como obreros. Y aun así, uno de ellos, Di Naie Zaitung (El Nuevo Diario), no representa a un gremio sino a un grupo de trabajadores del diario Di Idishe Tzaitung que, enfrentado con la dirección del periódico, decide emprender una publicación a partir de la formación de una cooperativa. ${ }^{14}$

A los efectos negativos del embate represivo, se le suman las consecuencias de la crisis económica por la que atraviesa el país durante parte de la segunda década del siglo XX y del estallido de la Primera Guerra Mundial. El debilitamiento de la economía tiene un efecto demoledor sobre el nivel de empleo y las condiciones de vida de los trabajadores y, en consecuencia, sobre la fuerza y posibilidad de organización de los sindicatos. Por otra parte, el inicio de la conflagración paraliza el crecimiento del sionismo en el país debido a que no sólo detiene momentáneamente la inmigración y con ella el arribo de activistas experimentados, sino 


\begin{tabular}{|c|c|c|c|c|c|}
\hline Nombre & $\begin{array}{c}\text { Años de } \\
\text { publicación }\end{array}$ & Lengua & Frecuencia & $\begin{array}{c}\text { Orientación } \\
\text { Ideológica }\end{array}$ & Pertenencia Institucional \\
\hline $\begin{array}{l}\text { Najriten } \\
\text { (Noticias) }\end{array}$ & 1906 & Idish & Diario & $\begin{array}{l}\text { Sionista } \\
\text { Socialista }\end{array}$ & $\begin{array}{c}\text { Editado por el Centro Sionista Socialista } \\
\text { precursor del Poalei Sión. Es } \\
\text { reemplazado por Dos Idishe Lebn. }\end{array}$ \\
\hline $\begin{array}{l}\text { Dos idische Leben } \\
\text { (La Vida Judía) }\end{array}$ & 1906 & Idish & Diario & $\begin{array}{c}\text { Sionista } \\
\text { Socialista }\end{array}$ & $\begin{array}{c}\text { Editado por el Centro Sionista Socialista } \\
\text { precursor del Poalei Sión }\end{array}$ \\
\hline $\begin{array}{l}\text { Undzer Lebn } \\
\text { (Nuestra Vida) }\end{array}$ & 1906 & Idish & Irreg. & $\begin{array}{c}\text { Sionista } \\
\text { Socialista }\end{array}$ & Órgano de los sionistas socialistas \\
\hline $\begin{array}{l}\text { Dos Arbeter Lebn } \\
\text { (Vida Obrera) }\end{array}$ & 1908 & Idish & Semanal & Anarquista & $\begin{array}{c}\text { De orientación anarquista, ligada al } \\
\text { Grupo Arbeter Fraind }\end{array}$ \\
\hline $\begin{array}{l}\text { Lebn un Fraihait } \\
\text { (Vida y Libertad) }\end{array}$ & 1908 & Idish & Mensual & Anarquista & $\begin{array}{c}\text { De orientación anarquista, ligada al } \\
\text { Grupo Arbeter Fraind }\end{array}$ \\
\hline $\begin{array}{c}\text { Der Avangard } \\
\text { (La Vanguardia) } 2 \\
\text { épocas } \\
\end{array}$ & $\begin{array}{l}1908-1910 \\
1916-1920\end{array}$ & Idish & Mensual & Bundista & $\begin{array}{l}\text { Org. Socialista Obrera Israelita } \\
\text { "Avangard"de orientación bundista }\end{array}$ \\
\hline $\begin{array}{l}\text { La Protesta, } \\
\text { página en el diario }\end{array}$ & 1908-1909 & Idish & Diario & Anarquista & $\begin{array}{l}\text { Una página en el diario anarquista en } \\
\text { castellano La Protesta }\end{array}$ \\
\hline $\begin{array}{c}\text { Di Shtime fun Avangard } \\
\text { (La Voz de la } \\
\text { Vanguardia) }\end{array}$ & 1909 & Idish & Mensual & Socialista & $\begin{array}{c}\text { Edit x los"iskrovzes".Reconocidos como } \\
\text { grupo idiomático del } \\
\text { PS, autodenominándose Ctro Avangard }\end{array}$ \\
\hline $\begin{array}{l}\text { Broit un Ehre } \\
\text { (Pan y Honra) }\end{array}$ & $1909-1910$ & Idish & Bisemanal & $\begin{array}{l}\text { Sionista } \\
\text { Socialista }\end{array}$ & $\begin{array}{l}\text { Órg del Poaleisión inmediatam luego de } \\
\text { fundado el núcleo y sumado el Ctro } \\
\text { Sionist Sclista }\end{array}$ \\
\hline $\begin{array}{c}\text { Unzer Vort } \\
\text { (Nuestra Palabra) }\end{array}$ & 1913 & Idish & Semanal & Bundista & $\begin{array}{c}\text { Independiente en 1911, luego bundista } \\
\text { en su nuevo período de } 1913\end{array}$ \\
\hline $\begin{array}{l}\text { Der Fraie Arbeter } \\
\text { (El Obrero Libre) }\end{array}$ & 1917 & Idish & - & Anarquista & $\begin{array}{c}\text { Perteneciente a los círculos anarquistas } \\
\text { racionalistas judíos }\end{array}$ \\
\hline $\begin{array}{l}\text { Di Naie Zeitung } \\
\text { (El Nuevo Diario) }\end{array}$ & 1917 & Idish & Irregular & Obrera & $\begin{array}{l}\text { Personal en huelga de Di Idishe Tzaitung } \\
\text { que da origen al diario progresista Di } \\
\text { Presse }\end{array}$ \\
\hline $\begin{array}{l}\text { Der Holtz Arbeter } \\
\text { (El Obrero Maderero) }\end{array}$ & $1917-1923$ & Idish & Mensual & Obrera & Sección judía del sindicato del mueble \\
\hline
\end{tabular}

Tabla 2. Publicaciones periódicas de izquierda nacidas entre 1906 y 1917

que además aísla a las organizaciones políticas de los centros europeos. Esta explicación acerca del impacto de la guerra sobre el sionismo socialista puede ser, sin embargo, extendida hacia las otras fuerzas políticas. De esta manera, no es sino hasta el fin de la Primera Guerra Mundial que la actividad política judía de izquierda vuelve a ganar relevancia.

Frente al clima adverso del período 19101917, el activismo obrero y la política progresista judía encuentran refugio en la acción cultural (fundación de bibliotecas, centros culturales y edición de algunas pocas publicaciones) y en el activismo intracomunitario. Si bien los argumentos a favor de la participación en las nacientes instituciones comunitarias judías no son los mismos, los sionistas socialistas y los bundistas coinciden en la necesidad de intervenir en la vida judía organizada. Por contrapartida, los anarquistas optan por no compromenterse en las batallas internas de la comunidad de la manera directa y activa en que lo hacen las otras organizaciones.

En esta etapa seminal de la izquierda judía argentina, la ampliación de la prensa política da lugar a una progresiva diferenciación de una serie de agentes respecto del más amplio conjunto de los militantes y trabajadores judíos. En efecto, la labor periodística abre la posibilidad para la emergencia de periodistas, escritores e intelectuales, cuyo sustento cada vez depende menos de labores distintas a las intelectuales. Esto permite una creciente especialización que deviene central para la configuración de un espacio en el cual, mediante la palabra impresa, se produce la apropiación y difusión de ideas provenientes de los polos judíos europeos, la transmisión de formas de autorrepresentación y representación de la realidad y el análisis de los acontecimientos internacionales y locales. En otras palabras, con estos agentes comienza a definirse un área diferenciada que actúa como mediadora entre distintos espacios sociales y universos ideológicos.

Así, si observamos con detenimiento los nombres de los directores, editores y colaboradores de la prensa progresista, podemos seguir los primeros pasos de las trayectorias intelectuales y políticas de algunas de las figuras centrales de la vida política y cultural judía 
argentina. El recorrido de Pinie Katz, tal vez el intelectual y dirigente más relevante de la izquierda de habla idish junto a Pinie Wald, resulta en este sentido paradigmático. Aparece por primera vez en la escena impresa en 1908, dos años después de su llegada al país, como colaborador en el periódico anarquista Lebn un Fraihait (Vida y Libertad). En el mismo año vuelve a estampar su presencia en la página en idish que editaba el diario anarquista La Protesta. Entre 1909 y 1910 su nombre figura como redactor y colaborador de la prestigiosa publicación sionista socialista Broit un Ehre (Pan y Honra), dirigida por León Jazanovich. Posteriormente, en 1913, se lo encuentra como director junto a Pedro Sprinberg de la revista mensual ilustrada Shtraln (Resplandores), que si bien puede ser definida como progresista en términos amplios, no poseía una definición ni afiliación política o ideológica explícita. Su nombre aparece una vez más como colaborador en el diario general en idish Der Tog (El Día), publicado entre 1914 y 1916 . Poco tiempo después ocupa el cargo de redactor en el diario en idish más importante de la colectividad judía, Der Idishe Zeitung (El Diario Israelita). De este jornal se desprende en 1917 un nuevo y efímero periódico, Di Naie Zeitung (El Nuevo Diario). Aquí ocupa el rol de editor junto a Israel Helfman, otro destacado periodista de la época. Este periódico da origen en 1918 al cotidiano progresista más relevante de la historia judía argentina, Di Presse (La Prensa). Del cual Pinie Katz no solo es uno de sus fundadores, sino también su director entre 1918 y fines de la década de 1930.

La importancia de Di Presse en el cambio del espacio de la prensa judía de izquierda lo sitúa, junto a la Declaración Balfour y la Revolución Rusa, como uno de los hitos que marcan el inicio del período siguiente.

\section{Emergencia y consolidación del comunismo}

La Declaración Balfour y la Revolución Bolchevique convierten al año 1917 en un parteaguas en la historia judía contemporánea. Así como el sueño sionista de un Estado propio en Palestina parece tras la Declaración más cerca que nunca, la caída del temido y odiado zar en manos bolcheviques inyecta un renovado vigor a las corrientes socialistas. ${ }^{15}$ De esta suerte, el impacto de ambos acontecimientos conduce a un reordenamiento del mapa político judío local. Tanto el sionismo socialista como el Bund sufren una profunda ruptura a partir del enfrentamiento entre una posición más inclinada hacia la clase y otra hacia algún grado de reivindicación nacional. Esta reestructuración del espacio político se ve condicionada por la fundación del Partido Comunista Argentino y de su Sección idiomática judía. Por otra parte, los efectos más importantes de estos eventos sobre el espacio de la prensa judía son, en primer lugar, la creación del clima propicio para la fundación y consolidación del cotidiano progresista en idish Di Presse en 1918, y, en segundo término, la multiplicación de publicaciones ligadas a la Sección Judía del PC. Di Presse pasa a ocupar de forma inmediata un lugar central dentro de la prensa judía en general y de izquierda en particular, constituyéndose en el punto de referencia a partir del cual el resto de las publicaciones políticas progresistas se van a posicionar. ${ }^{16}$ Este cotidiano se convierte en el medio de mayor alcance sobre el público obrero judío, y en uno de los principales polos de convergencia intelectual de la colectividad.

La afirmación y crecimiento de las distintas organizaciones políticas y de los gremios y secciones judías de los sindicatos generales, así como la emergencia del diario Di Presse y de un número importante de publicaciones partidarias a lo largo de la década de 1920 y 1930 , resultan posibles por la ampliación del público obrero judío de habla idish. Luego de finalizada la Primera Guerra Mundial tiene lugar una importante oleada inmigratoria judía que trae al país a obreros calificados de la industria textil y del vestido, en su mayoría polacos, que cuentan con una mayor tradición política y sindical que la mayoría de quienes los precedieron en su arribo al país. La presencia organizada judía dentro del movimiento obrero tiene su correlato en las publicaciones periódicas de los distintos gremios (ver Tabla 3).

Tras la reactivación general de las organizaciones de izquierda judía en el país en 1918, el Poalei Tzión comienza a editar ese mismo año el periódico mensual y luego semanal Di Naie Zeit (La Nueva Época). Tres años después, en su Segundo Congreso de 1921, el Sionismo Socialista en consonancia con lo que sucede en su organización internacional a partir de las discusiones en torno a la adhesión o no a la Tercera Internacional, se divide en dos partidos distintos, el Linke Poalei Tzión o Poalei Tzión de Izquierda y el Rejte Poalei Tzión o Poalei Tzión de Derecha. El primero logra incrementar su actividad política a lo largo de las décadas siguientes, mientras el segundo se estanca para reaparecer con mayor fuerza hacia fines de la década 1920 a través de las luchas institucionales comunitarias. ${ }^{17}$ A diferencia del Poalei Tzión de izquierda que se mantiene cercano pero independiente del Partido Comunista, el amplio sector del Bund que adhiere en 1920 a la Tercera Internacional ingresa al Partido Socialista Internacional, preámbulo del Partido Comunista argentino, para luego integrar la Idsektsie, la versión local de la Sección Judía del P.C. soviético. A lo largo de la década de 1920, el Poalei Tzión de Izquierda y el comunismo vía su sección idiomática, logran conquistar una posición dominante dentro del sector judío del movimiento obrero. ${ }^{18}$ 
La Sección Judía del comunismo inicia en 1923 su frondosa trayectoria editorial con la publicación del periódico semanal Der Roiter Shtern (La Estrella Roja). Entre su primer número en 1923 y 1934 , año de su cierre, esta publicación se erige como la columna vertebral de la prensa comunista judía. ${ }^{19}$ En torno a ella se multiplican las publicaciones comunistas en idish orientadas a temas y públicos específicos. En efecto, con una mayor o menor ligazón con el PC, a partir de 1926 comienzan a editarse periódicos y revistas culturales, educativas, ${ }^{20}$ infantiles, juveniles, y de apoyo a la colonización judía en Rusia y al proyecto de la región autónoma judía de Birobidjian. ${ }^{21} \mathrm{La}$ ruptura de Penelón con el PC en 1927 es acompañada por numerosos dirigentes de la Sección Judía que editan en 1928 el periódico mensual Tzum Kampf (A la Lucha). Con el advenimiento del nazismo en Europa, el problema del antisemitismo concentra gran parte de la actividad editorial comunista judía. ${ }^{22}$ Dentro de ella se encuentra Soviet, publicación que, a pesar de no haber sobrevivido a su primer número, es presentada como reemplazo de Der Roiter Shtern. La creación del Comité contra el Racismo y el Antisemitismo (más tarde Organización Popular contra el Antisemitismo), impulsa la edición de distintos periódicos destinados a combatir el fascismo. Luego, hacia el fin del período analizado, en 1940, aparece la revista ICUF. Sobre la base de los centros educativos, clubes sociales, culturales y deportivos existentes, se conforma en 1941 la Federación de Entidades Culturales Israelitas (Idisher Cultur Farband), cuyo nombre (ICUF) ya adelanta la revista. ${ }^{23}$

En el análisis de este período no puede obviarse el cimbronazo político y cultural producido por el pacto de no agresión firmado por Alemania y la Unión Soviética el 23 de agosto de 1939, conocido como Pacto Mólotov-von Ribbentrop. Si tenemos en cuenta la progresiva reorientación de los esfuerzos políticos e intelectuales de la izquierda judía en general y de los sectores cercanos al comunismo en particular hacia la lucha contra el fascismo y el antisemitismo proveniente de la Alemania nazi, resulta posible comprender el desconcierto producido por el sorpresivo acuerdo entre Stalin y Hitler. En este sentido, el historiador Leonardo Senkman acierta al señalar que los efectos locales de este acontecimiento ameritarían proponer un subperíodo dentro de la periodización aquí ofrecida. ${ }^{24}$ Algunos de estos efectos sobre el espacio de las publicaciones periódicas fueron indicados de manera pertinente por la historiadora Silvia Schenkolewski-Kroll en su estudio acerca de las polémicas dentro de la prensa de izquierda judía en el país. ${ }^{25}$ Asimismo debe considerarse en el estudio de estos efectos el reestablecimiento del sistema de referencias internacionales anterior al Pacto, cuando el territorio dominado por la
Unión Soviética es atacado por las fuerzas nazis en junio de 1941.

En el mismo año de su irrupción como nueva organización política, el Poalei Tzión de Izquierda comienza a editar la publicación bimensual Dos Arbeter Vort (La Palabra Obrera), pues Di Naie Zeit queda en manos del Poalei Tzión de Derecha. A la primera época de Dos Arbeter Vort, 1921-1923, le sigue una segunda época que se inicia en 1931. Ese mismo año el Poalei Tzión de Izquierda lanza un nuevo pero efímero periódico, Arbeter Kultur (Cultura Obrera). En 1932 el Movimiento Juvenil Jalutziano Gordonia, de orientación sionista pro obrera, emprende la edición de lugnt Veg (La Joven Senda). Al año siguiente el Partido Obrero Unido Sionista Socialista presenta Der Kampf(La Lucha), que no supera el año de vida. También en 1933, pero en este caso extendiéndose hasta 1939, la organización poaleisionista de izquierda Fraind fun Arbeter Palestine (Sociedad de Amigos de la Palestina Obrera) publica el periódico mensual Dos Arbeter Palestine (La Palestina Obrera). Entre 1933 y 1945 la Liga Pro-Obreros de Eretz Israel, organización sionista socialista, imprime la publicación quincenal Undzer Zait (Nuestra Era). La última de las publicaciones sionistas socialistas que corresponden al período analizado es el periódico borojovista lungt Avangard (Vanguardia Juvenil), editado entre 1934 y 1948.

El sector anarquista judío orientado hacia el anarco-comunismo publica entre 1918 y 1919 el periódico Broit un Fraihait (Pan y Libertad), y entre 1923 y 1925 el periódico mensual Di Fraihait Schtime (La Voz de la Libertad). En 1929 se funda el grupo anarco-comunista Arbet (Trabajo) que publica un periódico mensual del mismo nombre. En 1936 la Asociación Racionalista Judía publica Dos Fraie Vort (La Palabra Libre).

Por su parte, los militantes bundistas que no se incorporan al Partido Socialista Internacional logran reorganizar el partido en 1924 tras la llegada de nuevos inmigrantes polacos. De allí surge una nueva entidad que adopta el nombre de Unión Judía Bund Comité Buenos Aires. Ese mismo año comienzan a editar Der Arguentiner Béker (EI Alertador o Despertador Argentino). En 1929 la Unión Judía Bund se disuelve dentro de una organización mayor, la Unión Socialista Israelita de la Argentina, de la que también forman parte activistas de otras corrientes socialistas. Entre 1929 y 1930, esta organización publica de manera irregular Undzer Viln (Nuestra Voluntad). Su lugar es ocupado en 1930 por el periódico quincenal Socialistischer Bletter (Páginas Socialistas), que hasta 1933 imprime un total de 47 números. La última publicación que editan durante el período observado, es el bisemanario Arguentiner Lebn (Vida Argentina), entre 1936 y 1937.

El decidido avance comunista dentro del movimiento obrero judío y el desarrollo de un amplio abanico de propuestas culturales, 


\begin{tabular}{|c|c|c|c|c|}
\hline Nombre & $\begin{array}{c}\text { Años de } \\
\text { publicación }\end{array}$ & Lengua & Frecuencia & Pertenencia Institucional \\
\hline $\begin{array}{c}\text { Di Arbeit Shtime } \\
\text { (La Voz del Trabajo) }\end{array}$ & 1918 & Idish & Semanal & $\begin{array}{l}\text { Idisher Arbeter Organizatzie } \\
\text { (Organización Obrera Judía) }\end{array}$ \\
\hline $\begin{array}{l}\text { Di Arbeter Organizatsie } \\
\text { (La Organización Obrera) }\end{array}$ & 1920-1922 & Idish & Mensual & $\begin{array}{l}\text { Boletín del conjunto de los sindicatos judíos. } \\
\text { Participan de la organización que da lugar a } \\
\text { este boletín: ebanistas, sastres, gorreros, } \\
\text { panaderos y mozos }\end{array}$ \\
\hline $\begin{array}{l}\text { Biuletin fun Idisher Arbeter } \\
\text { Farband Far Guegnzáitiker Hilf } \\
\text { (Boletín de la Asoc. Obrera } \\
\text { Israelita de Ayuda Mutua) }\end{array}$ & 1920-1926 & Idish & - & Asociación Obrera de Ayuda Mutua \\
\hline $\begin{array}{c}\text { Nodl Arbeter } \\
\text { (Obrero de la Aguja) }\end{array}$ & 1922 & Idish & Irreg. & Sindicato de Sastres de Buenos Aires \\
\hline $\begin{array}{l}\text { Di Shtime fun Holtz Arbeter } \\
\text { (La Voz del Obrero Maderero) }\end{array}$ & 1924 & Idish & - & $\begin{array}{c}\text { Órgano de la Sección judía del sindicato } \\
\text { obrero de la industria del mueble. Pro-Israel } \\
\text { Obrera }\end{array}$ \\
\hline $\begin{array}{c}\text { Der Mebl Arbeter } \\
\text { (El Trabajador del Mueble) }\end{array}$ & $\begin{array}{l}1925- \\
1928 i ?\end{array}$ & Idish & Mensual & $\begin{array}{c}\text { Órgano de la Sección judía del sindicato } \\
\text { obrero de la industria del mueble }\end{array}$ \\
\hline $\begin{array}{c}\text { Di Javerte } \\
\text { (La Compañera) }\end{array}$ & 1929 & Idish & - & $\begin{array}{l}\text { Comité de Damas de los centros y clubes } \\
\text { obreros }\end{array}$ \\
\hline Publicación de los fasoniers & $193 i ?-193 i ?$ & Idish & - & Rama judía de los Fasoniers \\
\hline $\begin{array}{l}\text { Der Confectsion Arbeter } \\
\text { (El Trabajador de la Confección) }\end{array}$ & $1934-1938$ & Idish & - & $\begin{array}{c}\text { Unión Obrera de Cortadores, Sastres, } \\
\text { Costureras y Anexos } \\
\text { Secc Confecciones de la Federación Obrera } \\
\text { del Vestido }\end{array}$ \\
\hline $\begin{array}{l}\text { Der Schnaider Arbeter } \\
\text { (El Trabajador Sastre) }\end{array}$ & 1935 & Idish & Irregular & $\begin{array}{c}\text { Unión Obrera de Cortadores, Sastres, } \\
\text { Costureras y Anexos }\end{array}$ \\
\hline $\begin{array}{l}\text { Biuletin fun Heim Shnaider un } \\
\qquad \text { Talleristn Farein } \\
\text { (Boletín de la Unión de Sastres a } \\
\text { Domicilio y Talleristas) }\end{array}$ & 1937-1946 & Idish & Irregular & Unión de Sastres a Domicilio y Talleristas \\
\hline
\end{tabular}

Tabla 3. Publicaciones periódicas obreras judías entre 1918 y 1941.

educativas y políticas extensamente difundidas y sostenidas por una batería de publicaciones periódicas, habría incidido de manera significativa en la redefinición del área de acción del resto de las organizaciones de izquierda. El activismo cultural, la educacion judía laica y progresista y la denuncia de las prácticas políticas y la intolerancia comunista, propias del exclusivismo del «tercer período», adquieren un lugar central dentro de la agenda política y editorial del Bund, del anarquismo, del Poalei Tzión de Derecha, y del Poalei Tzión de Izquierda. No obstante, a partir del inicio de la década de 1930, el propio sector comunista de la colectividad judía presta cada vez más atención a la vida social y cultural, en desmedro de la acción política y obrera abierta. ${ }^{26}$ De este modo, es necesario contemplar la directa incidencia de la represión política anticomunista inaugurada por la dictadura uriburista y continuada en el tiempo a través de la Sección Especial contra el Comunismo de la Policía Federal, ${ }^{27}$ así como también considerar la decisión del PC de eliminar la Sección Judía ${ }^{28}$ y disolver el activismo étnico dentro del mundo obrero.

El nacimiento de Di Presse, como desprendimiento pro-obrero del cotidiano $D i$ Idishe Tzaitung, lo sitúa desde su misma aparición como contrapunto progresista de este último diario, que pasa a representar cada vez con mayor claridad a los sectores acomodados de la colectividad. Así, a partir de la emergencia de $D i$ Presse y de la oposición entre ambos diarios se estructura un nuevo espacio de la palabra impresa judía en el país con dos polos ideológicos enfrentados: progresismo en sus distintas versiones contra liberalismo y sionismo no socialista en términos amplios. Estructura del espacio de la prensa que, por otra parte, resulta 


\begin{tabular}{|c|c|c|c|c|c|}
\hline Nombre & $\begin{array}{l}\text { Años de } \\
\text { publicación }\end{array}$ & Lengua & Frecuencia & Temática & Pertenencia Institucional \\
\hline $\begin{array}{c}\text { Der Roiter Shtern } \\
\text { (La Estrella Roja) } 2 \text { épocas } \\
\end{array}$ & $\begin{array}{r}1923-1925 \\
1925-1934 \\
\end{array}$ & Idish & Semanal & Publicación general & Sección Judía del PC \\
\hline $\begin{array}{l}\text { lunger Komunizm } \\
\text { (Juventud Comunista) }\end{array}$ & $192 i ?-193 i ?$ & Idish & - & Juvenil & $\begin{array}{c}\text { Órgano de la sección judía de la Federación } \\
\text { Juvenil Comunista }\end{array}$ \\
\hline $\begin{array}{l}\text { Dorem Amérike } \\
\text { (Sudamérica) }\end{array}$ & $1926-1927$ & Idish & Mensual & Publicación Literaria & $\begin{array}{c}\text { De orientación comunista } \\
\text { (sin datos sobre afiliación directa) }\end{array}$ \\
\hline Boletín del PROKOR & 1927 & Idish & - & $\begin{array}{c}\text { Ayuda a los colonos israelitas } \\
\text { en la Rusia Soviética y en } \\
\text { Birobidjian }\end{array}$ & $\begin{array}{l}\text { PROKOR (Organización obrera pro ayuda a los } \\
\text { colonos israelitas en la Rusia Soviética) }\end{array}$ \\
\hline $\begin{array}{c}\text { Pioner } \\
\text { (Pionero) }\end{array}$ & $1927-1928$ & Idish & $\begin{array}{l}\text { Mensual- } \\
\text { Irregular }\end{array}$ & $\begin{array}{l}\text { Infantil. Paralela a } \\
\text { "Compañerito" }\end{array}$ & $\begin{array}{l}\text { "Federación Infantil de Pioners" de la sección } \\
\text { infantil de las escuelas Arbeter Shuln }\end{array}$ \\
\hline $\begin{array}{c}\text { Nai Velt } \\
\text { (Nuevo Mundo) }\end{array}$ & $1927-1930$ & Idish & Mensual & $\begin{array}{l}\text { Revista literaria de ideología } \\
\text { revolucionaria marxista }\end{array}$ & $\begin{array}{c}\text { De orientación comunista } \\
\text { (sin datos sobre afiliación directa) }\end{array}$ \\
\hline $\begin{array}{c}\text { Nai-Land } \\
\text { (Nueva Tierra) }\end{array}$ & 1928 & Idish & Mensual & $\begin{array}{l}\text { Public. de divulgación de } \\
\text { cultura, arte, crítica y letras }\end{array}$ & $\begin{array}{c}\text { PROKOR (Organización obrera pro ayuda a los } \\
\text { colonos israelitas en la Rusia Soviética) }\end{array}$ \\
\hline $\begin{array}{l}\text { Tzum Kampf } \\
\text { (A la Lucha) }\end{array}$ & 1928 & Idish & Mensual & - & $\begin{array}{l}\text { Penelonista. Órgano mensual del PC de la } \\
\text { Región Argentina }\end{array}$ \\
\hline $\begin{array}{l}\text { Der Idisher Poier } \\
\text { (El Campesino Judío) }\end{array}$ & $1928-1931$ & Idish & Irregular & - & $\begin{array}{l}\text { PROKOR (Organización obrera pro ayuda a los } \\
\text { colonos israelitas en la Rusia Soviética) }\end{array}$ \\
\hline $\begin{array}{c}\text { Roite Hilf } \\
\text { (Ayuda Roja) }\end{array}$ & $1928-1934$ & Idish & Irregular & - & $\begin{array}{l}\text { Subcomisión judía de la Ayuda Roja } \\
\text { Internacional (MOPR) }\end{array}$ \\
\hline $\begin{array}{c}\text { Undzer Schul } \\
\text { (Nuestra Escuela) }\end{array}$ & $1929 i ?$ & Idish & - & - & Comisión de padres de las Escuelas Obreras \\
\hline $\begin{array}{c}\text { Shul Wegn } \\
\text { (Sendas Escolares) }\end{array}$ & 193i?-193i? & Idish & Mensual & $\begin{array}{l}\text { Publicación de cuestiones } \\
\text { comunitarias y pedagógicas }\end{array}$ & - \\
\hline $\begin{array}{c}\text { Der Poier } \\
\text { (El Campesino) }\end{array}$ & $1932-1933$ & Idish & Irregular & $\begin{array}{l}\text { Continuación de Der Idisher } \\
\text { Poier }\end{array}$ & $\begin{array}{l}\text { PROKOR (Organización obrera pro ayuda a los } \\
\text { colonos israelitas en la Rusia Soviética) }\end{array}$ \\
\hline $\begin{array}{l}\text { Boletín del Comité Popular } \\
\qquad \text { para la... }\end{array}$ & $1933-1933 i ?$ & Castellano & - & - & $\begin{array}{c}\text { Comité Popular para la Ayuda a las Masas } \\
\text { Judías-Alemanas y para la Lucha contra el } \\
\text { Fascismo y el Antisemitismo }\end{array}$ \\
\hline $\begin{array}{l}\text { In Gang } \\
\text { (En Marcha) }\end{array}$ & $1933-1937$ & Idish & Mensual & $\begin{array}{l}\text { Publicación literaria. } \\
\text { Reemplaza a Nai Velt }\end{array}$ & $\begin{array}{l}\text { Comunista pero ya no como órgano de la } \\
\text { Sección Judía }\end{array}$ \\
\hline $\begin{array}{c}\text { Naie-Erd } \\
\text { (Nueva Tierra) }\end{array}$ & $1933-1940$ & Idish & - & $\begin{array}{c}\text { Continuación de Der Poier. } \\
\text { Apoyo a la colonización en } \\
\text { Birobidjian }\end{array}$ & $\begin{array}{l}\text { PROKOR (Organización obrera pro ayuda a los } \\
\text { colonos israelitas en la Rusia Soviética) }\end{array}$ \\
\hline Soviet & 1934 & Idish & Un número & $\begin{array}{l}\text { Reemplaza a Der Roiter Shtern } \\
\text { Publicación antifascista }\end{array}$ & $\begin{array}{l}\text { Comité judío del COMPARTAl, sección judía del } \\
\text { Comintern }\end{array}$ \\
\hline $\begin{array}{l}\text { Oif der Waj } \\
\text { (En Guardia) }\end{array}$ & $1934-1941$ & Idish & Quincenal & Publicación antifascista & Organización Popular contra el Antisemistmo \\
\hline Alerta & $1935-1943$ & Castellano & - & - & Organización Popular contra el Antisemistmo \\
\hline $\begin{array}{c}\text { Nai -Teater } \\
\text { (Teatro Nuevo) }\end{array}$ & $1935 i ?$ & Idish & - & Revista de Teatro & $\begin{array}{l}\text { Órgano de la agrupación dramática IFT, en ese } \\
\text { momento Idramst }\end{array}$ \\
\hline $\begin{array}{c}\text { Main Shul Javer } \\
\text { (Mi Compañero de Escuela) }\end{array}$ & $1935 i ?$ & Idish & Mensual & Revista educativa & - \\
\hline $\begin{array}{l}\text { Zeitshrift } \\
\text { (Revista) }\end{array}$ & $1935 i ?$ & $\begin{array}{c}\text { Idish } / i \\
\text { Castellano? }\end{array}$ & & & $\begin{array}{c}\text { Órgano de la Comisión central de patronatos } \\
\text { judíos de Socorro Rojo Internacional }\end{array}$ \\
\hline En Guardia & $1937-i ?$ & Castellano & & Publicación antifascista & Organización Popular contra el Antisemistmo \\
\hline $\begin{array}{c}\text { Di Voj } \\
\text { (La Semana) }\end{array}$ & 1938 & Idish & Semanal & & \\
\hline $\begin{array}{c}\text { Di Folk Shtime } \\
\text { (La Voz del Pueblo) }\end{array}$ & $1940-1942$ & Idish & $\begin{array}{l}\text { Sem; } 2 \vee \times \\
\text { sem;diario }\end{array}$ & & \\
\hline ICUF, Revista & 1940-1949¿? & Idish & Mensual & & $\begin{array}{l}\text { Revista que precede a la Federación de } \\
\text { Instituciones Culturales Israelitas, ICUF }\end{array}$ \\
\hline
\end{tabular}

Tabla 4. Publicaciones comunistas, en su mayoría vinculadas al Partido Comunista, cuyo primer número fue editado entre 1923 y 1940.

posible y logra perdurar en el tiempo en la medida en que los dos cotidianos, situados en polos opuestos, se orientan y ligan a sectores sociales y políticos distintos, a los que, por otra parte, contribuyen a dar existencia. ${ }^{29}$ Pero también es posible constatar la centralidad de esta oposición al repasar el conjunto de escritores e intelectuales encolumnados tras ambos proyectos. Por el lado de Di Idishe Tzaitung se agrupan un conjunto de periodistas, escritores e intelectuales ligados en diversos momentos de sus trayectorias a proyectos periodísticos generales o sionistas de centro. Por el de Di Presse circulan periodistas e intelectuales vinculados a periódicos y revistas 
de las diversas orientaciones de izquierda. Cada diario funciona así como una red de sociabilidad y formación intelectual, como instancia de elaboración y difusión de discursos políticos diferenciados, y como puente de contacto con el mundo judío del exterior. ${ }^{30}$

\section{Ascenso social, apuesta cultural y cambio lingüístico}

Si bien la elección de 1941 como apertura del cuarto período remite a la fundación en Argentina de la Federación de Entidades Culturales Israelitas (Idisher Cultur Farband, ICUF), organización de orientación comunista, la etapa abarca y en alguna medida se define por una serie de transformaciones sociales y culturales de gran relieve en el desarrollo del espacio de las publicaciones periódicas de izquierda. A pesar de que estas transformaciones pueden ser detectadas mucho tiempo antes del inicio de este período, es con el correr de las décadas de 1940 y 1950 que fenómenos como la desproletarización general de la colectividad judía y el reemplazo del idish por el castellano como lengua dominante se tornan visibles y sus efectos sobre el espacio de las publicaciones de izquierda se hacen perceptibles. A estos procesos de más larga duración se suman tres acontecimientos políticos internacionales que tienen un fuerte impacto sobre el derrotero de la política judía en la Argentina. En primer lugar, entre 1939 y 1945, la Segunda Guerra Mundial y la Shoá. Luego, en 1948, la creación del Estado de Israel. Y, finalmente, los juicios de corte antisemita llevados a cabo en el bloque soviético entre 1952 y 1953 contra intelectuales y médicos judíos. Dentro de la esfera de la izquierda judía en el país se producen dos eventos de importancia para nuestro análisis. La fundación del ICUF en 1941, por una parte, y su salida/expulsión de las instituciones centrales de la comunidad en 1952 luego de las controversias en torno a los juicios y ejecuciones mencionadas, por la otra. En el plano local los eventos que exhiben efectos más directos sobre la prensa judía de izquierda son las exigencias lingüísticas (limitaciones al uso de una lengua extranjera) de la dictadura militar de $1943^{31}$, del gobierno peronista ${ }^{32}$ y de la persecusión del comunismo. ${ }^{33}$

La acumulación y ritmo de los cambios socioeconómicos y culturales de la colectividad judía le otorgan durante este período un nuevo aspecto. En las décadas de 1940 y 1950 los procesos de desproletarización y cambio lingüístico respectivamente se amplían hasta abarcar a una mayoría de la población. Si hacia mediados de la década de 1930 la presencia de un área judía dentro del movimiento obrero argentino inicia un marcado descenso debido al cambio de postura del comunismo respecto de los clivajes étnicos, la década siguiente muestra una sensible y progresiva disminución de individuos judíos en las filas obreras en razón del ascenso socioeconómico general del colectivo judío. Tendencia que se muestra más aguda si consideramos la emergencia de un nuevo sector industrial que, al tiempo que amplía y diversifica las bases obreras, disminuye el peso demográfico relativo judío dentro de los sindicatos. De esta manera, el último periódico estrictamente obrero que registramos comienza a ser publicado en el período anterior, en 1937, y concluye en 1946.

Por otra parte, en los primeros años de la década de 1950 el cambio idiomático se hace palpable. A pesar de no reflejar la clausura definitiva del idish como lengua cotidiana de cierta parte de la población judía, la década de 1950 es el momento en que el peso del castellano inclina por primera vez, pero ya de manera irrevocable, la balanza lingüística judía a su favor. Si bien los lectores en idish siguen constituyendo hasta al menos mediados de la década de 1970 un núcleo de relativa importancia, es entre 1950 y 1953 que declina hasta prácticamente desaparecer el número de nuevas publicaciones periódicas exclusivamente en idish. De allí en adelante, salvo contadas excepciones, las publicaciones son bilingües o completamente en castellano. ${ }^{34}$ Esto es un proceso general del universo de las publicaciones periódicas judías en Argentina (no así del mundo del libro que revela una lógica diferente) y no tan sólo un fenómeno de la izquierda. En este marco se agudizan las discusiones en torno al idioma que debe prevalecer como lengua representativa de los judíos argentinos. En realidad, más allá de una coyuntural victoria ideológica a favor del idish, del hebreo, o del castellano, lo cierto es que no parece haber márgenes para una vuelta hacia atrás respecto al avance de esta última lengua.

De las 16 publicaciones periódicas identificadas como pertenecientes al espectro de la izquierda judía dentro de este período, 8 se hallan redactadas integramente en idish, 5 son bilingües (de las cuales una, el Boletín del Grupe David Edelstadt, inferimos que cuenta con alguna sección en castellano) ${ }^{35}$ y las 3 restantes totalmente en castellano. Del conjunto, 9 están ligadas de alguna manera al sector comunista de la colectividad. Al menos dos de ellas son editadas directamente por el ICUF. Luego, encontramos 3 publicaciones sionistas socialistas, dos anarquistas, una de las cuales es un boletín, y una bundista. La preeminencia numérica del comunismo durante este período se ve reforzada si tomamos en cuenta que lanzan dos emprendimientos periódicos diarios, Der Veg (La Senda) y Haint (Hoy). Se puede conjeturar que el esfuerzo por introducir estos dos cotidianos dentro del espacio de la prensa judía está 


\begin{tabular}{|c|c|c|c|c|}
\hline Nombre & $\begin{array}{c}\text { Años de } \\
\text { publicación }\end{array}$ & Lengua & Frecuencia & Pertenencia Institucional \\
\hline $\begin{array}{c}\text { Undzer Veg } \\
\text { (Nuestra Senda) }\end{array}$ & $194 i ?$ & Idish & - & Ligado a sectores comunistas \\
\hline $\begin{array}{c}\text { Undzer Vort } \\
\text { (Nuestra Palabra) }\end{array}$ & 1944-1964¿? & Idish & - & Partido sionista socialista Adjut Avodá \\
\hline $\begin{array}{l}\text { Der Veg } \\
\text { (La Senda) }\end{array}$ & $1945-1949 i ?$ & Idish & Diario & Ligado a sectores comunistas \\
\hline En marcha & $1946-1949$ & Castellano & Quincenal & $\begin{array}{c}\text { Ligado a sectores comunistas, "periódico de la juventud } \\
\text { progresista" }\end{array}$ \\
\hline $\begin{array}{c}\text { Undzer Guedank } \\
\text { (Nuestro } \\
\text { Pensamiento) } \\
\end{array}$ & $1947 i ?$ & Idish & - & Bundista \\
\hline $\begin{array}{l}\text { Di Velt } \\
\text { (El Mundo) }\end{array}$ & $1947-1950$ & Idish & - & De orientación anarquista \\
\hline $\begin{array}{c}\text { Naie Tzait } \\
\text { (Nuevo Tiempo) }\end{array}$ & $1947-1963$ & Idish & Semanal & Sionista socialista, MAPAI \\
\hline $\begin{array}{l}\text { Nueva Sión } \\
2 \text { épocas }\end{array}$ & $\begin{array}{c}1948-1977 \\
(1984-2007)\end{array}$ & Cast. & - & $\begin{array}{c}\text { De la Fundación Mordejai Anilevich, órgano del partido } \\
\text { socialista israelí Mapam-Hashomer Hatzair }\end{array}$ \\
\hline $\begin{array}{l}\text { Haint } \\
\text { (Hoy) }\end{array}$ & $1948-1950$ & Idish / Castellano & Diario & Ligado a sectores comunistas \\
\hline $\begin{array}{c}\text { Landsmanschaften } \\
\text { (Org. } x \text { lugar de } \\
\text { origen) }\end{array}$ & 1948-1963 ¿? & Idish / Castellano & Quincenal & $\begin{array}{l}\text { Patronato x nacionalides adherido al Socorro Rojo } \\
\text { Internacional, de orientación comunista }\end{array}$ \\
\hline $\begin{array}{l}\text { Heymland } \\
\text { (Patria) }\end{array}$ & 1949-1956¿? & Idish & - & $\begin{array}{l}\text { Edic. periód. de la Soc. Cult. Israelita "Birobidyan". } \\
\text { Fareyn fun idishe Sovietishe birger in Argentine }\end{array}$ \\
\hline Tribuna & $1950-1971$ ¿? & Idish / Castellano & Semanal & Ligado a sectores comunistas \\
\hline $\begin{array}{l}\text { Di Idishe Froi } \\
\text { (La Mujer Judía) }\end{array}$ & $1950-1969$ & Idish / Castellano & Bimest./Irreg. & ICUF \\
\hline $\begin{array}{l}\text { Biuletin } \\
\text { (Boletín) }\end{array}$ & $1952-1960$ & Idish / ¿ Castellano? & - & Grupe David Edelstadt, anarquista \\
\hline Aporte & $1953-1956$ & Castellano & Bimestral & ICUF (reemplaza a la revista ICUF) \\
\hline $\begin{array}{c}\text { Dos Naie Vort } \\
\text { (La Nueva Palabra) } \\
3 \text { épocas }\end{array}$ & $1953-1970$ & Idish & Mensual & $\begin{array}{l}\text { Órgano oficial de la Tnuat Haavodá Hazionit, grupo } \\
\text { juvenil sionista socialista }\end{array}$ \\
\hline
\end{tabular}

Tabla 5. Publicaciones periódicas de izquierda fundadas entre 1941 y 1953.

vinculado en alguna medida a la distancia que toma Di Presse, el cotidiano progresista más importante de la colectividad judía local, de las posturas del PC. ${ }^{36}$ Sin embargo, el menor número de periódicos sionistas socialistas se ve compensado, por una parte, con la duración de dos de ellos, Nueva Sión y Dos Naie Vort, y, por la otra, con una tendencia ascendente en el número de nuevas publicaciones hacia fines del período analizado, lo cual hace preveer el crecimiento numérico que se prolonga en el período siguiente. Dentro del sionismo socialista en términos amplios, Nueva Sión reviste un lugar clave como columna vertebral del sionismo de izquierda en lengua castellana, posición que consolida a lo largo del tiempo. ${ }^{37}$

De entre las distintas causas que explican la fuerza del comunismo y la contracción del bundismo hacia 1941, la Segunda Guerra Mundial y la Shoá son comunes a ambas. Mientras en el primer caso el rol soviético en el triunfo aliado implica una revalorización del comunismo, en el segundo, la destrucción de las comunidades judías polacas y lituanas, centros simbólicos y políticos del Bund, supone el debilitamiento del proyecto político bundista. A esto hay que añadir dos causas locales. El PCA, incluso bajo la persecusión y el peronismo, es un partido con una militancia muy disciplinada, de fuerte impacto cultural y de gran ascendencia sobre sectores de clase media urbana de reciente ascenso, tal como lo es el núcleo judío que lo apoya. Por el contrario, el Bund se encuentra actuando en un contexto político en el cual no hay margen para una apuesta de autonomía nacional-cultural, tal como sí lo había en Polonia, a lo cual se agrega su adhesión a un partido, el socialista, que rechaza cualquier tipo de división étnica en su seno. El declive del anarquismo como movimiento político comienza mucho antes de 1941 y para esta etapa su acción está más vinculada a la educación y la cultura. 
Por su parte, el sionismo de izquierda, que siempre ha tenido una base de activistas importante, capitaliza políticamente la creación del Estado de Israel. El nacimiento y consolidación del periódico Nueva Sión ${ }^{38}$ y la aparición de nuevos periódicos sionistas socialistas de relevancia son un claro resultado de ello.

Hay un fenómeno que la tabla no expresa, pero que resulta importante para un posterior estudio de los periódicos en particular. Nos referimos a la modificación de la postura del sector comunista respecto a «lo judío»y a la comunidad judía, que se cristaliza con la fundación del ICUF y la participación de éste de las instancias comunitarias centrales. En efecto, la combinación entre persecución política al comunismo, que fortalece la entidades culturales periféricas al partido, la decisión del Partido de eliminar las secciones étnicas dentro de los sindicatos, la desproletarización general de los judíos, la experiencia del activismo antifascista y antinazi de la década de 1930, el impacto de la Shoá, y, tal vez podríamos agregar, cierto temor a la pérdida de la continuidad judía, conducen a la opción comunista por una identificación más explícita con la cultura judía y a la decisión de participar en las instancias comunitarias. ${ }^{39}$ El ICUF emerge de esta manera como el espacio institucional en el cual «lo judío» y la identidad comunista pueden ser compatibilizadas.

Pero el acercamiento político se convierte en un movimiento pendular cuando las instituciones del ICUF son expulsadas de las instituciones centrales de la comunidad en 1953. En otras palabras, el ICUF no sólo se mantiene firme en su negativa a reconocer y condenar el carácter antisemita de los juicios contra intelectuales y médicos judíos llevados a cabo en la Unión Soviética, sino que, además, reivindica su posición procurando demostrar públicamente su capacidad de supervivencia como espacio institucional judío. ${ }^{40}$

Sin embargo, tal como adelantamos, el proceso de reemplazo de una lengua por otra excede la ocasional decisión acerca de su preservación o reproducción en el tiempo por parte de los dirigentes. Éstos pueden otorgarle al idish o al hebreo un determinado sentido en función de la ideología, pueden enseñarlas en sus colegios, pero no parecen poder revertir la tendencia hacia el desplazamiento de una lengua por otra. ${ }^{41}$ Este proceso de reemplazo tiene consecuencias fundamentales para la configuración del espacio de las publicaciones periódicas judías. De hecho, debido a la importancia que este cambio reviste para el presente análisis, hemos tomado a 1953 como cierre del período.
Un veloz recorrido por el conjunto de las publicaciones de izquierda muestra el claro dominio del idish por sobre las otras lenguas. Esto supone la existencia de un público lector y de un conjunto de escritores, intelectuales y periodistas, que leen y producen en esta lengua. Es decir, se conforma un espacio público de producción, circulación y consumo de mensajes diferenciado del medio argentino, a partir del uso del idish. De manera que el paso de una lengua a otra conlleva, más allá de los matices, a un cambio en el público y en los propios agentes productores. Hay, por ende, un nuevo recorte socio-cultural. Pero, por otra parte, también implica cambios en las conexiones con polos externos a la colectividad judía argentina. Si antes los vínculos con los centros de habla idish en el exterior eran directos y con el entorno argentino en castellano precisaban ser mediados por la traducción, ahora, esto se invierte, estableciéndose una conexión directa del público lector y de los intelectuales de habla castellana con el medio local y una relación mediada por la traducción con los centros idish y hebreos en el exterior. ${ }^{42}$ Esto revela, en última instancia, el problema para producir un espacio público específicamente judío. En efecto, este problema aparece, y de manera más pronunciada aún para parte de la izquierda cuyo discurso diferenciador ha sido reducido a un mínimo, cuando tanto el lector como el intelectual pueden participar del más amplio espacio público argentino fundado sobre la palabra impresa en castellano.

\section{Algunas palabras finales}

El recorrido por las publicaciones periódicas judías de izquierda en Buenos Aires que hemos realizado nos revela las contornos de un espacio denso de producción, circulación y consumo de bienes simbólicos conformado por un conjunto de intelectuales, periodistas, escritores y militantes políticos situados en el país y en el exterior, y por un público lector con características singulares, que se diferencia de los espacios de publicaciones más generales, judío por una parte, y argentino por la otra. La objetivación de este espacio nos ofrece un terreno de investigación inexplorado.

En el presente estudio hemos analizado las líneas generales del proceso de modernización de una de las dimensiones de la prensa judía en el país. Sin embargo, en tanto primer acercamiento, hemos dejado de lado la información acerca del volumen de tiradas, formas de venta, publicidad, precio en función de los salarios de los trabajores, etc, cuyo estudio contribuiría a dar más alcance y precisión, o bien a matizar o rectificar, las tendencias y procesos aquí descriptos. Por otra parte, hemos 
considerado solo de manera superficial el lugar del lector, revés necesario para la existencia de un espacio de publicaciones. En este sentido, el trabajo invita a una indagación más profunda acerca de la conformación, ampliación y diversificación del público lector.

De manera complementaria a estas dimensiones sociales y materiales, el trabajo deja planteada la necesidad de abordar a un conjunto de agentes escasamente estudiados que tuvieron un rol decisivo en la elaboración del espacio de publicaciones periódicas judías. En efecto, identificar y relevar las trayectorias de un conjunto de intelectuales, periodistas, escritores, editores y militantes políticos que participaron en la producción, mediación y puesta en circulación de una serie de ideas, permitiría dar densidad y complejidad al espacio sobre el que aquí nos hemos concentrado. En el mismo sentido, un plano que deliberadamente hemos puesto en suspenso es el del análisis de los contenidos de las publicaciones. Sólo los hemos tratado en un sentido muy general en la medida en que resultó preciso para describir las posiciones de cada publicación, las tensiones entre sí y las grandes transformaciones históricas del conjunto. ${ }^{43} \mathrm{De}$ esta manera, consideramos que superponer y entrelazar estos distintos niveles de análisis contribuiría a la comprensión de los rasgos singulares de esta área social, cultural y política, y los modos en que ella refractó los procesos y acontecimientos externos en función de su lógica interna.

Ciudad de Córdoba, 8 de agosto 2008

\section{Bibliografía}

Álbum 50 años de la Prensa Judía Progresista en la Argentina. 1923-1973, 1973, ICUF, Buenos Aires.

Bacci, C. 2005. Las políticas culturales del progresismo judío argentino: Ia revista Aporte y el ICUF en la década de 1950, Políticas de la Memoria-Anuario de Investigación e Información del CeDInCl, N ${ }^{\circ}$ 5, Verano 2004/ 2005: 159-168.

Bilsky, E. 1987. Etnicidad y clase obrera: la presencia judía en el movimiento obrero argentino, El movimiento obrero judío en la Argentina. Tomo I, Centro de Documentación e Información sobre Judaísmo Argentino «Marc Turkow», AMIA, Buenos Aires.

Bourdieu, P. 1990. Sociología y Cultura, Grijalbo, Madrid.

Camarero, H. 2007. A la conquista de la clase obrera. Los comunistas y el mundo del trabajo en la Argentina, 1920-1935. Siglo Veintiuno Editora Iberoamericana, Buenos Aires.

Chartier, R. 1990. História Cultural. Entre práticas e representações, Editora Bertrand Brasil, S.A., Rio de Janeiro.

Grusman, I.L. 1941. Las Letras Hebreas en Argentina, Judaica, Nro doble 97-98, Buenos Aires: $49-51$

Itzigsohn, S.1985. Integración y marginalidad. Historias de Vidas de Inmigrantes Judíos en la Argentina, Ed. Pardes, Buenos Aires.

Katz, P. 1982. Páginas selectas, Ed. ICUF, Buenos Aires.

Laubstein, I. 1997. Bund: Historia del movimiento obrero judío, Acervo Cultural Editores, Buenos Aires.

Lewin, B. 1971. Cómo fue la inmigración judía a la Argentina, Plus Ultra, Buenos Aires.

Mendelsohn, E. 2003. On Modern Jewish politics, Oxford University Press, Nueva York.

Mintz, M. 1997. Ber Borochov, en Mendelsohn, Ezra (comp) Essential Papers on Jews and the Left, New York University Press, Nueva York: 122-144

Mírelman, V. 1988. En búsqueda de una identidad. Los inmigrantes judíos en Buenos Aires, 1890-1930, Milá, Buenos Aires.

Moya, J. 2004. The positive side of stereotypes: Jewish anarchists in early-twentieth-century Buenos Aires en Jewish History 18, Kluwer Academic Publishers, Holanda: 19-48

Regalsky, M. 1941. Los Partidos Políticos Judíos, Judaica, Nro doble 97-98, Buenos Aires: 51-54

Rein, R, y M. Lewise. 2007. Complementary Identities: Sephardim, Zionists and Argentines between the Two World Wars, Pe'amim, Studies in the Cultural Heritage of Oriental Jewry, No 111-112, Israel: 79-102

Rollansky, S. 1941. El periodismo, las letras y el teatro judíos en la Argentina, Judaica Nro 94, Buenos Aires: 179-189

Schallman, L. 1977. «Historia del periodismo judío en la Argentina» en Comunidades Judías de América Latina, Comité Judío Americano, Buenos Aires: 149-173

Schenkolewski-Kroll, S. 2007. La prensa judía de izquierda en Argentina - los periódicos en 
idish hasta mediados del siglo $X X$, ponencia inédita presentada en las IV Jornadas de Historia de las Izquierdas «Prensa política y emprendimientos editoriales de las izquierdas latinoamericanas», Buenos Aires.

Schers, D. 1992. Inmigrantes y política: los primeros pasos del Partido Sionista Socialista Poalei Sion en la Argentina, 1910-1916, Estudios Interdisciplinarios de América Latina y el Caribe, volumen $3-\mathrm{N}^{\circ} 2$, Tel Aviv: $75-88$

Svarch, A. 2005. El comunista sobre el tejado. Historia de la militancia comunista en la calle judía (Buenos Aires, 1920-1950), tesis de licenciatura en historia inédita, Buenos Aires.

Toker, E. y A. Weinstein. 1999. Trayectoria de una Idea. Nueva Sión: 50 años de periodismo judeoargentino con compromismo, 1948-1998, Ediciones Fundación Mordejai Anilevich, Buenos Aires.

Traverso, E. 2006. Los marxistas y la cuestión judía, Ed. Al Margen, La Plata.

Visacovsky, N. 2007. Di idishe froi: Imágenes de la mujer judeo progresista argentina durante el peronismo, ponencia inédita presentada en las IV Jornadas de Historia de las Izquierdas «Prensa política y emprendimientos editoriales de las izquierdas latinoamericanas», Buenos Aires.

Zadoff, E. 2004. Historia de la educación judía en Buenos Aires (1935-1957), Milá, Buenos Aires.

1 Este análisis es parte de una investigación de más largo aliento en la que procuramos explorar un conjunto de procesos sociales a través de los cuales se elaboraron, circularon y disputaron una serie ideas acerca de «lo judío» dentro de la colectividad judía argentina.

2 Chartier, Roger, 1990, «Historia intelectual e histórica das mentalidades: una dupla reavaliação», en História Cultural. Entre práticas e representações, Editora Bertrand Brasil, S.A., Rio de Janeiro. Pp. 29-67.

${ }^{3}$ La decisión de registrar en una primera instancia las publicaciones periódicas editadas en la Ciudad de Buenos Aires y no las impresas en otras localidades del país se debe, en primer lugar, a la centralidad política, cultural y social de la comunidad judía de Buenos Aires sobre la vida judía del resto de las ciudades del país. En términos demográficos esta asimetría resulta elocuente. Si en 1909 entre el $51,4 \%$ y el $56,5 \%$ de los judíos se hallaban dispersos entre el Litoral, la región pampeana y la Capital Federal, hacia 1934 el 51,8\% reside en Capital Federal, y entre 1947 y 1960 ese porcentaje aumenta a más del $66,5 \%$. Aumento al cual podemos añadir el notable incremento poblacional en distritos de la Provincia de Buenos Aires adyacentes a la circunscripción de la Capital Federal.
La acción política y cultural que allí se desarrolla tiene efectos decisivos sobre el conjunto de las comunidades del país. En segundo lugar hay una razón de orden metodológico. La posibilidad de construir un registro relativamente amplio de las publicaciones periódicas del resto del país resulta, por diversos motivos, una tarea en extremo ardua que excede las posibilidades y necesidades del presente trabajo. No obstante ello, hemos incluido dos periódicos bisemanales publicados en Entre Ríos (uno de ellos luego trasladado a Buenos Aires) en razón de su relevancia dentro del proceso colonizador judío. Incluimos uno más, también abocado a temas relativos a la colonización, del que desconocemos su lugar de origen preciso pero acerca del cual tenemos la firme sospecha de que es publicado fuera de Buenos Aires.

4 Incluimos dentro de la categoría de izquierda a todas aquellas publicaciones que se reconocen o han sido reconocidas como partícipes de esa zona del espacio ideológico-político, y que comprende las siguientes denominaciones y sus variantes: izquierda, progresista, socialista, anarquista, comunista, obrera, bundista y marxista.

${ }^{5}$ Para una lectura más específica de los judíos comunistas ver Svarch, Ariel, 2005, El comunista sobre el tejado. Historia de la militancia comunista en la calle judía (Buenos Aires, 1920-1950), tesis de licenciatura en historia inédita, Buenos Aires y Camarero, Hernán, 2007, A la conquista de la clase obrera. Los comunistas y el mundo del trabajo en la Argentina, 1920-1935. Siglo Veintiuno Editora Iberoamericana, Buenos Aires, Pp. 297-311.

${ }^{6}$ Dada la extensión máxima posible para el presente texto nos detenemos en 1953, dejando para posteriores trabajos el estudio de las tres décadas siguientes. EI corte en este año se debe a que, tal como desarrollaremos, hacia mediados de la década los efectos del progresivo desplazamiento del idish al castellano sobre el espacio de las publicaciones periódicas se hacen más notorios.

7 Luego de su ejemplar número 20 Najriten es reemplazado por el diario Dos Idishe Lebn (La Vida Judía) cuya vida es aun más breve que la de su antecesor, 17 días.

${ }^{8}$ Mendelsohn (1993) incluye otras dos corrientes centrales en la historia judía de Euopa Central, Occidental y de Estados Unidos: integracionistas y religiosos ortodoxos. Debido a su escaso peso político relativo durante el período que analizamos no revisten mayor importancia para la organización del campo político judío argentino. No obstante, la ausencia de trabajos historiográficos al respecto así como la riqueza cultural de las distintas experiencias en estos campos, abren una interesante agenda académica.

9 Para un análisis más pomenorizado de la ideología del Poalei Tzión Ver Mintz (1997) y Traverso (2006)

${ }^{10}$ Schers (1992) señala que en las cercanías de Plaza Lavalle de la Ciudad de Buenos Aires, zona de fuerte concentración judía en la primera década del siglo XX, era posible adquirir por aquellos años los periódicos Arbeter Fraind (Amigo Obrero) de Londres y Fraier Arbeter Schtime (La Voz del Trabajador Libre) de Nueva York.

"A la par de la prensa política que gana presencia a lo largo de este período, pueden encontrarse publicaciones de frecuencia diaria, semanal, quincenal, mensual y bimensual que apuntan a gustos, intereses y necesidades cada vez más diferenciados de la creciente población judía: periódicos de sectores comerciales, cooperativistas, de información general, de información 
acerca de eventos sociales, revistas culturales, publicaciones orientadas hacia la «asimilación»o hacia la «integración» cultural, de habla idish, castellana, bilingüe idish-castellano y árabe, etc. Un caso relevante por la confluencia entre redactores sefaradíes y ashkenazíes, por su duración (1917-1970), por redactarse íntegramente en castellano, por haberse editado durante un breve período cinco veces por semana, y por la especial apropiación y uso del sionismo realizado, es el del periódico Israel. Para una aproximación a las diversas dimensiones y problemas abiertos por esta publicación, ver Rein y Lewis (2007).

12 Para un análisis de la presencia judía en el movimiento anarquista en Argentina en las primeras décadas del siglo XX ver José Moya (2004) y para el de los primeros años del partido Poalei Tzión en Argentina, David Schers (1992)

${ }^{13}$ Aunque las razones puntuales de la expulsión de Sorkin y sobre todo de Jazanovich se vinculan a luchas políticas intrajudías antes que a cuestiones políticas argentinas más amplias, su deportación se legitima en el clima político general de persecución política (Schers 1992) El activista e intelectual progresista Pinie Katz incluye otros nombres no siempre citados: «...el socialdemócrata Mashevitz, y del grupo «Arbeter Fraind» Moishe Shut, lavitz, Samburski y otros.» (Katz 1982:33)

${ }^{14}$ Al respecto, Bilsky señala: «A pesar de la agitación social reinante en Buenos Aires entre 1900 y 1910 , el asalariado judío carecía aún de una tradición sindicalista y no era propenso a aceptar la disciplina del gremio. Se sentía ajeno al movimiento general, no entendía -por las trabas idiomáticas - la propaganda y le resultaba difícil comunicarse o identificarse, tanto en el taller como en el sindicato, con los trabajadores no judíos. Por ende quedaba limitado a una presencia pasiva, pues no intervenía en los debates ni en la vida de la sociedad de resistencia.» (Bilsky 1987:39)

15 La Declaración Balfour, considerada por el movimiento sionista como el primer reconocimiento formal internacional de los derechos del pueblo judío sobre la Tierra de Israel y como una de las bases de la creación del Estado de Israel, es un breve texto en el que el Reino Unido se declara favorable a los planes sionistas de creación de un hogar nacional judío en Palestina. Su nombre proviene de su firmante, el secretario del Foreign Office (ministro de Relaciones Exteriores) británico, Arthur James Balfour.

16 La larga vida de Di Presse, 1918-1994, dificulta encasillarlo en una unica posición. Los distintos contextos políticos así como el natural recambio de directores y redactores, lo conducen a continuas redefiniciones. Así, a modo de ejemplo, Bilsky (1987:95) señala que la creciente intolerancia soviética hacia la crítica y hacia el sionismo durante la década de 1920 y parte de la de 1930, al menos hasta el planteo de la posición de los «Frentes Populares», conduce al fin del apoyo que hasta allí Di Presse y Mundo Israelita le habían dispensado al Partido Comunista. Mucho más adelante en el tiempo, en 1973, un libro homenaje a los 50 años de la prensa judía progresista (comunista) en el país, escrito por un miembro del ICUF (siglas en idish de la Federación de Entidades Culturales Israelitas) dice acerca de Di Presse: «...diario que si en los primeros años de existencia se vinculó a las causas populares, hace mucho que se enroló en el más estridente chauvinismo judío y destila un odio a muerte a todo lo que representa progresismo y socialismo.» (50 años de la Prensa Judía Progresista en Argentina, 1973: 6). Con ello el autor del texto marca, desde el punto de vista comunista, el viraje sionista del cotidiano.

17 Su presencia se incrementa significativamente a partir de su unificación con el partido sionista progresista Tseirei-Tzión en 1932.

18 De acuerdo a Bilsky (1987), las fracciones comunistas penetraron en los gremios judíos $y$ desplazaron velozamente a la dirigencia anarquista y bundista. Así, hacia fines de 1924, la Sección Judía se atribuía el dominio de los sindicatos de gorreros, sastres, textiles y del mueble, así como también el control de la Biblioteca Obrera de Villa Crespo y a la Folks Bibliotek (Biblioteca Popular), rebautizada con el nombre de Biblioteca Central Obrera.

19 Según Svarch (2005:21), Der Roiter Shtern tenía en 1927 un tiraje de 3.500 ejemplares, más de la mitad que su par en castellano, "La Internacional» (con un tiraje de 6000) y superando al italiano, «Ordine Nuovo», a pesar de que la sección italiana era numéricamente superior a la judía.

20 Desde mediados de la década de 1920 y hasta la clausura policial de 1932, la Sección Judía logró desarrollar y sostener una red escolar propia.

${ }^{21}$ En 1924 se crea el PROKOR (Organización obrera pro ayuda a los colonos israelitas en la Rusia Soviética) con la intención de apoyar la productivización de los judíos en Rusia y más tarde la colonización en Birobidjan: «EI PROKOR estuvo formado en sus inicios por representaciones de organizaciones (Roite Hilf, Idsektsie, sindicato del mueble, de pintores, textiles, los poalei sión de izquierda, la Biblioteca O. de Villa Crespo, la Biblioteca Central Obrera, la Idishe Fraie Bibliotek y la Unión General de Trabajadores Israelitas). En 1926 se reestructura aceptando afiliaciones individuales. Realiza en 1927 su primer congreso con 38 delegaciones de todo el país y 2.316 afiliados.» (Bilsky 1987:92, 93)

22 El problema del antisemitismo europeo y sus repercusiones vernáculas ocuparon los esfuerzos y energía de todo el espectro político judío. En una estrategia similar a la comunista, aunque anterior $y$ desde el polo opuesto, el Partido Socialista Judío Unificado Poalei Sión-Tseirei Sión impulsa el nacimiento del comité contra el antisemitismo que luego da origen a la Delegación de Asociaciones Israelitas de la Argentina (DAIA).

${ }^{23}$ En la década de 1930 el PCA cambia su postura acerca de los grupos idiomáticos disolviendo la Sección Judía y las secciones étnicas dentro del movimiento obrero argentino. De acuerdo a Bilsky, esto implicó la reorientación hacia la esfera cultural. El paso hacia esta esfera de acción fue posible gracias las estrategias previas dispuestas por la Sección Judía. Según el autor, a lo largo de la década de 1920 y hasta su disolución, la Idsektise se preocupó por expandir un «frente cultural» fuera de su acción gremial «...mediante publicaciones políticas y literarias y utilizando los espacios existentes en las bibliotecas y asociaciones mutuales, o creando nuevos centros especialmente concebidos: los clubes deportivos y los Arbeter Clubn (Clubes Obreros)» (Bilsky 1987:61).

${ }^{24}$ Este señalamiento fue realizado por Senkman en su generosa lectura y crítica de una de las versiones preliminares del presente estudio.

${ }_{25}$ La historiadora Silvia Schenkolewski Kroll (2007) dice al respecto: «Durante los 20 [Di Presse] fue el periódico judío argentino reconocido por la Unión Soviética (...) La primera brecha entre Di Presse y la política soviética fue cuestionar y no justificar el pacto 
entre Alemania y la Unión Soviética, tema que se solucionó con la invasión nazi a Rusia. (...) La polémica que despertó el pacto soviético alemán puso en absurdo la postura de la izquierda judía, cuyo vocero de aquel momento Der Tog defendía la política la Unión Soviética alegando que se trataba de una guerra entre potencias capitalistas. La prensa sionista socialista no pudo definirlos con otro epíteto que el de «impuros políticos», comparando a los judíos comunistas con los tratantes de blancas [en alusión a la Zwi Migdal, red judía de tratantes de blancas que existió en Argentina a principios del siglo $X X$ y que fue combatida con vehemencia por la comunidad judía]. Este enfrentamiento se transformó en esclarecimiento, cuando Rusia se alió a Gran Bretaña, Francia y Estados Unidos.» Cabe mencionar que, al igual que en el caso de Senkman, la lectura y comentarios de la Dra. Schenkolewski resultaron en aportes fundamentales para el desarrollo de este trabajo.

26 Para un análisis más acabado de esta redefinición estratégica de los partidos judíos de izquierda resulta necesario observar lo que ocurre con el resto de las instancias y organizaciones políticas de la colectividad, pues allí también habrían habido cambios significativos en este mismo sentido.

27 El estudio de la incidencia de estos procesos políticos sobre la actividad política de izquierda en general y sobre la judía en particular, contribuye a la comprensión de una serie de cambios en el espacio específico de la prensa progresista. La persecución política, el cierre de periódicos identificados con la izquierda, y la exigencia de utilizar el castellano en reemplazo o como complemento obligatorio de las lenguas extranjeras, posee efectos significativos y directos sobre la configuración del espacio impreso judío a lo largo del siglo XX.

28 Svarch añade un dato importante acerca de la organización política del sector judío del PC tras la disolución de la Idseksie: "Las secciones idiomáticas desaparecieron de forma oficial, aunque durante toda la década del 30 -y la década posterior- la dirección general del movimiento progresista judío, así como la institución de militancia de los askanim (activistas) y la propagación de la línea partidaria, estuvieron bajo control de un consejo conocido como «La Sección». Este organismo era una troika elegida por el Partido, que mantenía un férreo control de las actividades de los askanim y al que reportaban las células comunistas de cada institución progresista.» (Svarch 2005:26)

${ }^{29}$ Este enlace puede observarse en los testimonios de militantes políticos y obreros de las diversas corrientes de izquierda. En ellos se destaca con recurrencia la relevancia que Di Presse guarda como forma de acceso a información de suma importancia para este sector social, así como acerca de su rol como vocero de sus intereses

${ }^{30}$ Acerca de la relación con el exterior, el periodista e intelectual Samuel Rollansky dice: «La base del diario [Di Idishe Tsaitung] es la información, pero ofrece asimismo colaboraciones de los más destacados escritores judíos del exterior.»(Rollansky 1941:182) Rasgo que se acentúa para el caso de Di Presse: "Sus colaboradores habituales no son locales -como ocurre con «El Diario Israelita» [Di Idishe Tsaitung], en el que hallan ubicación los periodistas que se radican entre nosotros- sino autores famosos del exterior.» (Rollansky 1941:183)

31 La limitación más importante en este sentido durante este período fue la negativa del correo a repartir publicaciones que no contengan páginas en castellano.

32 Estas políticas pueden considerarse como expresiones políticas extremas de un discurso nacionalista heterófobo, que, bajo diversas manifestaciones, actúa a lo largo del siglo como telón de fondo ante el cual la colectividad judía debe «negociar» su lugar, su identidad como grupo diferenciado, dentro de la sociedad argentina.

33 Sin embargo, uno de los factores locales con consecuencias más regulares y directas sobre la prensa judía fue la economía. Las pronunciadas oscilaciones de la economía argentina a lo largo del siglo han determinado, con cierta frecuencia, cierres de publicaciones y cambios en muchas otras.

34 En la decisión del cambio también deben considerarse las exigencias y presiones políticas y culturales del gobierno argentino. Aunque como telón de fondo y como proceso más estable se halla la progresiva asimilación lingüística.

${ }^{35}$ Si bien sería pertinente mencionar y analizar aquí los cambios en las opciones lingüísticas de algunas publicaciones, la extensión del presente artículo nos impide adentrarnos en este punto. Di Idishe Froi, por ejemplo, opta de manera decidida por el bilingüísmo tres años después de haber sido creada. Acerca de esta publicación en particular, ver Visacovsky (2007).

${ }^{36}$ Un dato importante en este sentido, que debe ser valorado en el contexto de un análisis específico sobre el diario Di Presse o en el marco de estudios de trayectorias intelectuales, es el reemplazo de Pinie Katz por el de Jacobo Botoshansky en la dirección del periódico a fines de la década de 1930.

37 Al respecto ver Toker y Weinstein (1999)

38 En realidad Nueva Sión comienza a publicarse poco más de un mes de antes de la fundación del Estado de Israel, al calor del optimismo luego de la Declaración de Partición de Palestina de Naciones Unidas en 1947.

${ }^{39}$ Svarch explica que «...la Segunda Guerra los Ilevó a cuestionarse su postura de permanecer separados de las instituciones tradicionales; la comunidad, asimismo, dejó atrás parte de su rechazo a los comunistas y entreabrió las puertas de las instituciones centrales. Comenzó entonces la batalla por el control de las instituciones de la colectividad. El ICUF entraría a la DAIA en 1947 y aun antes, a partir de 1944, comenzó a presentarse a las elecciones de la ex Jevra Kedusha, la AMIA.» (Svarch 2005:48)

40 Acerca de los efectos culturales de esta separación, Svarch señala: «Esta exaltación de la ruptura se vio complementada con un movimiento cultural análogo aunque de signo opuesto al que siguió la AMIA y las instituciones allegadas al Vaad Hajinuj: allí donde estos ahondaron su giro hacia el hebreo e Israel, los progresive se acercaron al castellano y a la sociedad general. En 1952 vio la luz la revista «Aporte», donde participaron tanto participantes del movimiento progresista como intelectuales no judíos -aunque, claro, ideológicamente afines-; esta publicación, destinada a la «calle general», era toda en castellano.»(Svarch 2005:62)

${ }^{41}$ Las tensiones y debates ideológico-identitarios dentro del ICUF en torno al problema de las lenguas durante este período, se encuentran en las páginas de la revista Aporte (1953-1956). Para un análisis de esta publicación ver Bacci, Claudia (2005).

42 Bacci, al analizar la posición asumida por la dirección del ICUF en torno al cambio lingüístico, dice: «Para cumplir con el objetivo de «revisar críticamente» una herencia cultural amalgamada, Aporte no sólo se preocupa por la traducción del idish al castellano, y viceversa, sino que promueve un centro de estudios en castellano y la creación de un cuerpo de traductores. La revisión crítica atañe tanto a la herencia judía, a través de notas de crítica y discusión política, como a la herencia argentina, de la mano de recordatorios y homenajes a personajes de la historia y la política locales. En el número doble de junio de 1954, Aporte convoca a personas para tareas de traducción, y también a los 


\section{A. Dujovne}

nuevos creadores judíos progresistas que producen sus obras en castellano, a participar de la revista y de otras actividades a desarrollar en ICUF: un Seminario de Cultura Judía, una Editorial ICUF en castellano, un Centro de lecturas en castellano, y un amplio Programa Cultural con cursos literarios, espectáculos artísticos, «revistas orales». Llama también a los intelectuales judeoargentinos que escriben en castellano a aportar artículos sobre historia, arte, teatro y cultura general.( $n^{\circ} 4-5$, pág. 100)»(Bacci 2005:10).
43 Bourdieu (1990) ha demostrado la importancia de tener presente el carácter sistémico que adquieren las relaciones que establecen determinados agentes, instituciones o, en este caso publicaciones periódicas interesados en disputar el dominio de cierto capital para comprender la posición ocupada por cada uno de ellos en un momento dado, así como los cambios de posición a partir de las transformaciones históricas por las que atraviesa ese espacio social. 